\title{
Free Anterolateral Thigh Perforator Flap for Head and Neck Cancer Resection in a Nonagenarian
}

\section{Frank Lin, Damien Grinsell}

Department of Plastic and Reconstructive Surgery, St Vincent’s Hospital, Fitzroy, Australia.

Email: flin27@gmail.com

Received November $21^{\text {st }}, 2011$; revised January $5^{\text {th }}, 2012$; accepted January $15^{\text {th }}, 2012$

\begin{abstract}
With an aging population, free flap reconstruction for head and neck cancer ablation in the elderly is becoming more commonplace. In nonagenarians, however, such major operations are still rarely offered due to its physiological demands. We report the first case of successful resection and reconstruction of head and neck cancer with a free perforator flap in a 96 year old patient. We feel that with careful patient and flap selection, careful preoperative workup and close collaboration between treating teams, age alone should not preclude patients from receiving the best possible curative treatment and reconstruction in head and neck cancers. Even in nonagenarians, perforator free flaps, such as the anterolateral thigh flap, can be used safely to achieve good functional and aesthetic outcomes.
\end{abstract}

Keywords: Nonagenarian; Elderly; Microsurgery; Perforator Flap; Head and Neck

\section{Introduction}

As the technique of microvascular free tissue transfer become more commonplace in reconstructive surgery, many technical and philosophical boundaries are been challenged by pioneering surgeons. In the very elderly, however, free tissue transfer for head and neck reconstruction remain a technique often avoided due to a real or perceived concern regarding medical fitness and risks of complication. Often, these concerns are well justified. However, increasing numbers of studies have also shown free tissue transfer to be a safe technique in the elderly. With a rapidly aging population, multidisciplinary head and neck teams will no doubt face increasingly difficult decisions regarding the management of octogenarians and nonagenarians. We feel that provided appropriate consideration have been given to patient selection, flap selection and perioperative care, free tissue transfer can be safely performed in this population.

\section{Case Report}

A 96 year old lady presented to our institution with a T4N0M0 biopsy proven squamous cell carcinoma of the right floor of mouth involving the lateral segment of mandible. Despite her age the patient was in remarkably good health and lived in a low level care residence. She was a non smoker, with a past history of hypertension, and was free from other cardiac, respiratory and renal comorbidities. After careful consideration at our head and neck multidisciplinary meeting, a plan was made for wide local excision, segmental mandibulectomy, right supraomohyoid neck dissection and a soft tissue free flap reconstruction.

The patient was carefully worked up preoperatively which included attendance at a combined pre-anaesthetic clinic. She was clinically examined by her anaesthetist and a general physician for evidence of occult medical co-morbidities such as cardiac murmurs and carotid bruits. Investigations included a respiratory function tests, transthoracic echocardiography and a thallium stress test. The patient was preadmitted to the medi-hotel ward on the night prior to surgery for final assessment and intravenous hydration. Plans were made for invasive haemodynamic monitoring intraoperatively with an arterial line and an intensive care unit bed was arranged for postoperative care. In addition, she was assessed by a speech pathologist and dietician preoperatively.

A free anterolateral thigh (ALT) perforator flap was selected as the ideal soft tissue reconstruction. A $12 \times 6 \mathrm{~cm}$ fasciocutaneous flap was raised on a single intramuscular perforator. The size of the flap adequately addressed the dead space left by the $55 \mathrm{~mm}$ mandibular resection. As flap harvest was performed concurrently with the ablative surgery, it was ready for transfer at the conclusion of the resection. This minimized the overall operating time, with microvascular anatomosis and flap insetting taking an additional 70 minutes after the resection was complete. Microvascular anastomosis was performed using the facial 
artery and external jugular vein, with meticulous attention paid to the selection and positioning of pedicles to avoid kinking of calcified vessels. The total operating time was $5 \frac{1}{2}$ hours.

The patient recovered well on a plastics/ENT ward with no major complications. In addition to a standard regimen of intravenous antibiotics and thrombo-prophylaxis, she received particular attention to post operative physiotherapy, volume and electrolyte monitoring given her advanced age and higher risk of complications. She made a very good recovery, recommencing oral intake on day 9 and was discharged from hospital on day 19. Histology showed a poorly differentiated squamous cell carinoma of $35 \times 20$ $\mathrm{mm}$ with clear histological margins. There were no metastatic cervical lymph nodes, and based on patient and family wishes no adjuvant radiation therapy was given. At six months post surgery, there was no evidence of recurrence or local flap complications. She has good symmetry in her facial contour and is able to have a soft diet, allowing her to remain at her previous low level care residence (Figures 1-3).

\section{Discussion}

Free flap reconstruction for head and neck cancer resection as part of a multidisciplinary team is now widely accepted as the standard of care in many major centres. With Australia's population of over 65 year olds projected to reach $26 \%$ by 2051 [1], such complex operations performed on the very elderly will no doubt become more commonplace. It is well established that advanced age is an independent predictor for perioperative complications, mortality, and increased length of stay [2-4]. Safe and successful outcomes, therefore, will hinge on a combination of careful peri-operative care and sound surgical planning with an emphasis on close collaboration between multiple treating teams.

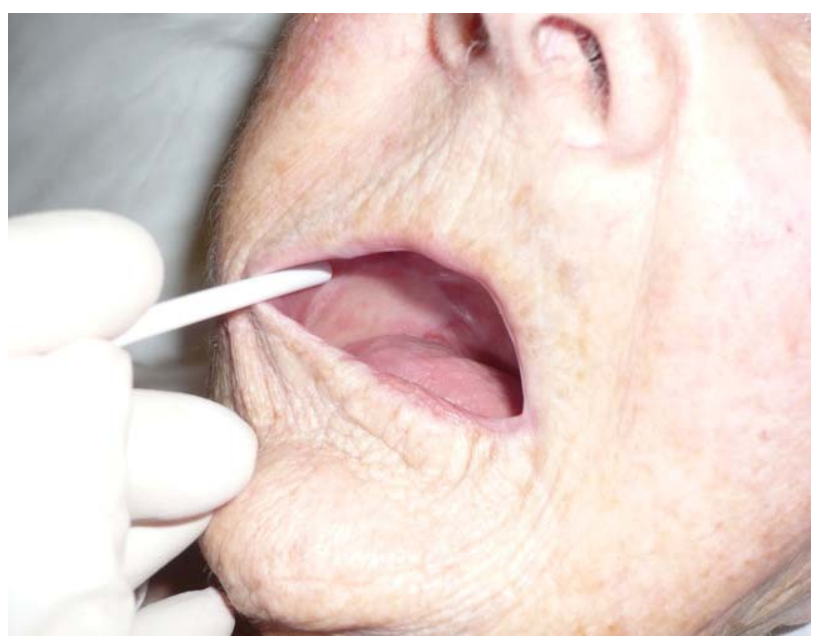

Figure 1. Intraoral flap inset at six months.

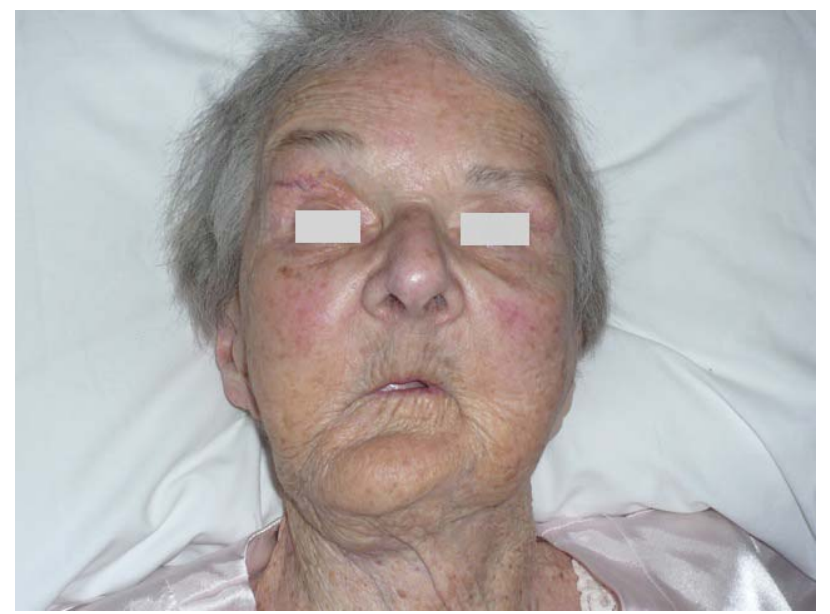

Figure 2. Patient facial contour at six months.

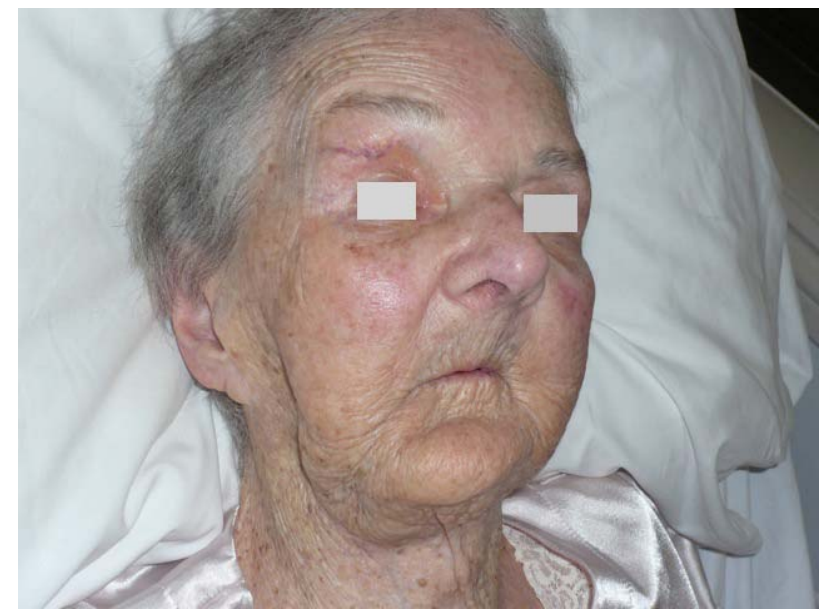

Figure 3. Patient facial contour at six months.

Perioperatively the patient should be thoroughly assessed by a multidisciplinary anaesthetic and medical team. Firstly, a more rigorous physiological evaluation may be required for cardiovascular, respiratory and renal systems. This is particularly relevant in a population where occult co-morbidities are more prevalent and physiological reserves are diminished [3,4]. Additional geriatric specific assessments may be required, including an assessment of overall functional status, nutrition and cognitive status [4]. Particularly in the oncogeriatric population, tools such as the Amercian Society of Anaesthesiologists (ASA) score and the Preoperative Assessment of Cancer in the Elderly (PACE) instrument may be invaluable [5]. A strong emphasis is also placed on intraoperative care which often require invasive cardiovascular monitoring, careful maintanence of core temperature and volume status. Involvement of the intensive care unit for perioperative care is often prudent in view of potentially long operating times on elderly patients. Finally, close collaboration between medical and nursing staff will serve to minimize respiratory, thromboembolic and pressure related complications 
postoperatively.

From a technical standpoint, free flap reconstruction in the elderly presents certain unique challenges. Firstly, flap selection is an important consideration. In our institution the free ALT perforator flap has become a workhorse flap in head and neck reconstruction. Described by Song [6], it is now widely considered an ideal soft tissue flap [7], with particular advantages in head and neck reconstruction providing a large, thin and pliable flap with a long pedicle $[8,9]$. In addition, it produces minimal donor site morbidity and allows for a two team approach to minimize overall operating time. These features make it particularly attractive in the elderly population. In addition, vessels may be heavily calcified necessitating extreme care in flap raising and perforator dissection. Microvascular anastomosis is often more challenging technically with higher risk of injury to vessels from the suture needle or microvascular clamps. Finally, selection of recipient vessels and orientation of the flap must also take into account the higher risk of kinking calcific vessels at the site of the microvascular anastomosis.

There are a small number of articles in the English literature examining outcomes and technical considerations in free flap surgery for the very elderly (Table 1).

Shestak et al. reviewed their experience with microvascular free tissue transfer in a large series of 92 patients over the age of 50 . They concluded that age alone does not compromise the success of free flaps, and that a higher perioperative complication rate is more likely to be associated with higher rates of medical co-morbidities [10]. In a large retrospective series examining free flap reconstruction in 100 consecutive patients over the age of 65, Serletti et al. also concluded that age should not be a contraindication for free flap transfer, and that the ASA status and operative time are significant predictors of medical and surgical morbidity [11]. Chick et al. and Coskunfirat et al. produced similar findings in populations groups of over 65 and 70s [12,13]. Specific to octogenarians, Blackwell et al. published their experience in free flap head and neck reconstruction in 13 patients and found it a reliable reconstructive method, albeit one associated with a higher

Table 1. Published series on free flap surgery in elderly.

\begin{tabular}{lllll}
\hline Author & $\begin{array}{l}\text { No. of } \\
\text { patients }\end{array}$ & $\begin{array}{l}\text { Minimum } \\
\text { age }\end{array}$ & $\begin{array}{l}\text { Flap loss } \\
\text { rate }\end{array}$ & $\begin{array}{l}\text { Mortality } \\
\text { rate }\end{array}$ \\
\hline Sestak et al. (1991) & 92 & 50 & $1 \%$ & $5 \%$ \\
Chick et al. (1992) & 31 & 65 & $6.4 \%$ & $0 \%$ \\
Malata et al. (1995) [15] & 42 & 70 & $4.7 \%$ & $3 \%$ \\
Serletti et al. (1999) & 100 & 65 & $3 \%$ & $3 \%$ \\
Ozkan et al. (2005) [16] & 55 & 50 & $1.7 \%$ & $5.4 \%$ \\
Coskunfirat et al. (2005) & 94 & 70 & $4 \%$ & $1 \%$ \\
\hline
\end{tabular}

likelihood of medical complications and higher associated economic cost [14].

To the best of our knowledge, the oldest patient to undergo free flap surgery to date in the literature was a 97 year old patient, who received a free radial forearm flap to resurface a non-graftable defect in her zygomatic area after tumour ablation [17]. Again, this patient was in remarkably good health despite her chronological age and lived independently. Prior to this Furnas described the reconstruction of a scalp defect using a free radial forearm flap in a 91 year old patient [18]. To our knowledge, our patient is the oldest in the literature to receive a free perforator flap and the oldest to undergo successful free flap intraoral reconstruction.

No doubt, the success of our case is in no small part due to the good general health and motivation of our patient. However, with close collaboration between the various treating teams, we feel that age alone should not preclude patients from receiving the best possible curative treatment and reconstruction in head and neck cancers. Even in nonagenarians, perforator free flaps, such as the ALT flap, can be used successfully to achieve good functional and aesthetic outcomes.

\section{REFERENCES}

[1] ABS, Australian Bureau of Statistics Life Table, 2009.

[2] L. L. Liu and J.M. Leung, "Predicting Adverse Postoperative Outcomes in Patients Aged 80 Years or Older," Journal of the American Geriatrics Society, Vol. 48, No. 4, 2000, pp. 405-412.

[3] C. A. Polanczyk, E. Marcantonio, L. Goldman, et al., "Impact of Age on Perioperative Complications and Length of Stay in Patients Undergoing Noncardiac Surgery,” Annals of Internal Medicine, Vol. 134, No. 8, 2001, pp. 637-643.

[4] M. Stefan, L. I. Lino and G. Fernandez, "Medical Consultation and Best Practices for Preoperative Evaluation of Elderly Patients,” Hospital Practice, Vol. 39, No. 1, 2011, pp. 41-51. doi:10.3810/hp.2011.02.373

[5] R. Audisio, H. Ramesh, W. Longo, et al., "Preoperative Assessment of Surgical Risk in Oncogeriatric Patients," The Oncologist, Vol. 10, No. 4, 2005, pp. 262-268. doi:10.1634/theoncologist.10-4-262

[6] Y. G. Song, G. Z. Chen and Y. L. Song, “The Free Thigh Flap: A New Free Flap Concept Based on the Septocutaneous Artery," British Journal of Plastic Surgery, Vol. 37, No. 2, 1984, pp. 149-159. doi:10.1016/0007-1226(84)90002-X

[7] H. C. Chen and Y. B. Tang, "Anterolateral Thigh Flap: An Ideal Soft Tissue Flap," Clinics in Plastic Surgery, Vol. 30, No. 3, 2003, pp. 383-401. doi:10.1016/S0094-1298(03)00040-3

[8] J. S. Chana and F. C. Wei, "A Review of the Advantages of the Free Anterolateral Thigh Flap in Head and Neck Reconstruction,” British Journal of Plastic Surgery, Vol. 
57, No. 7. 2004, pp. 603-609.

doi:10.1016/j.bjps.2004.05.032

[9] F. Farace, V. E. Fois, A. Manconi, et al., "Free Anterolateral Thigh Flap versus Free Forearm Flap: Functional Results in Oral Reconstruction," Journal of Plastic, Reconstructive \& Aesthetic Surgery, Vol. 60, No. 6, 2007, pp. 583-587. doi:10.1016/j.bjps.2006.11.014

[10] K. C. Shestak and N. F. Jones, "Microsurgical Free-Tissue Transfer in the Elderly Patient,” Plastic \& Reconstructive Surgery, Vol. 88, No. 2, 1991, pp. 259-263.

doi:10.1097/00006534-199108000-00014

[11] J. M. Serletti, J. P. Higgins, S. Moran, et al., "Factors Affecting Outcome in Free-Tissue Transfer in the Elderly,” Plastic \& Reconstructive Surgery, Vol. 106, No. 1, 2000, pp. 66-70. doi:10.1097/00006534-200007000-00012

[12] L. R. Chick, R. L. Walton, W. Reus, et al., "Free Flaps in the Elderly," Plastic \& Reconstructive Surgery, Vol. 90, No. 1, 1992, pp. 87-94. doi:10.1097/00006534-199207000-00013

[13] O. Coskunfirat, H. Chen, S. Spanio, et al., "The Safety of Microvascular Free Tissue Transfer in the Elderly Population,” Plastic \& Reconstructive Surgery, Vol. 115, No.
3, 2005, pp. 771-775. doi:10.1097/01.PRS.0000152424.91250.A5

[14] K. E. Blackwell, B. Azizzadeh, C. Ayala and J. D. Rawnsley, "Octogenarian Free Flap Reconstruction: Complications and Cost of Therapy," Otolaryngology-Head and Neck Surgery, Vol. 126, No. 3, 2002, pp. 301-306. doi:10.1067/mhn.2002.122704

[15] C. Malata, R. Cooter, A. Batchelor, et al., "Microvascular Free Tissue Transfers in Elderly Patients: The Leeds Experience,” Plastic \& Reconstructive Surgery, Vol. 98, No. 7, 1996, pp. 1234-1241. doi:10.1097/00006534-199612000-00018

[16] O. Ozkan, H. E. Ozgentas, K. Islamoglu, et al., "Experiences with Microsurgical Tissue Transfers in Elderly Patients,” Microsurgery, Vol. 25, No. 5, 2005, pp. 390-395. doi:10.1002/micr.20136

[17] M. Talbi, J. D. Stussi, D. Schwenk, et al., "Successful Radial Forearm Free Flap for Facial Reconstruction in a 97-Year-Old Patient,” Plastic \& Reconstructive Surgery, Vol. 106, No. 7, 2000, pp. 1656-1657. doi:10.1097/00006534-200012000-00046

[18] D. Furnas and J. Bernstein, "Free Flap in Nonagenarian," Plastic \& Reconstructive Surgery, Vol. 70, No. 1, 1982, pp. 116-117. doi:10.1097/00006534-198207000-00032 